Journal of

Materials Chemistry B Materials for biology and medicine

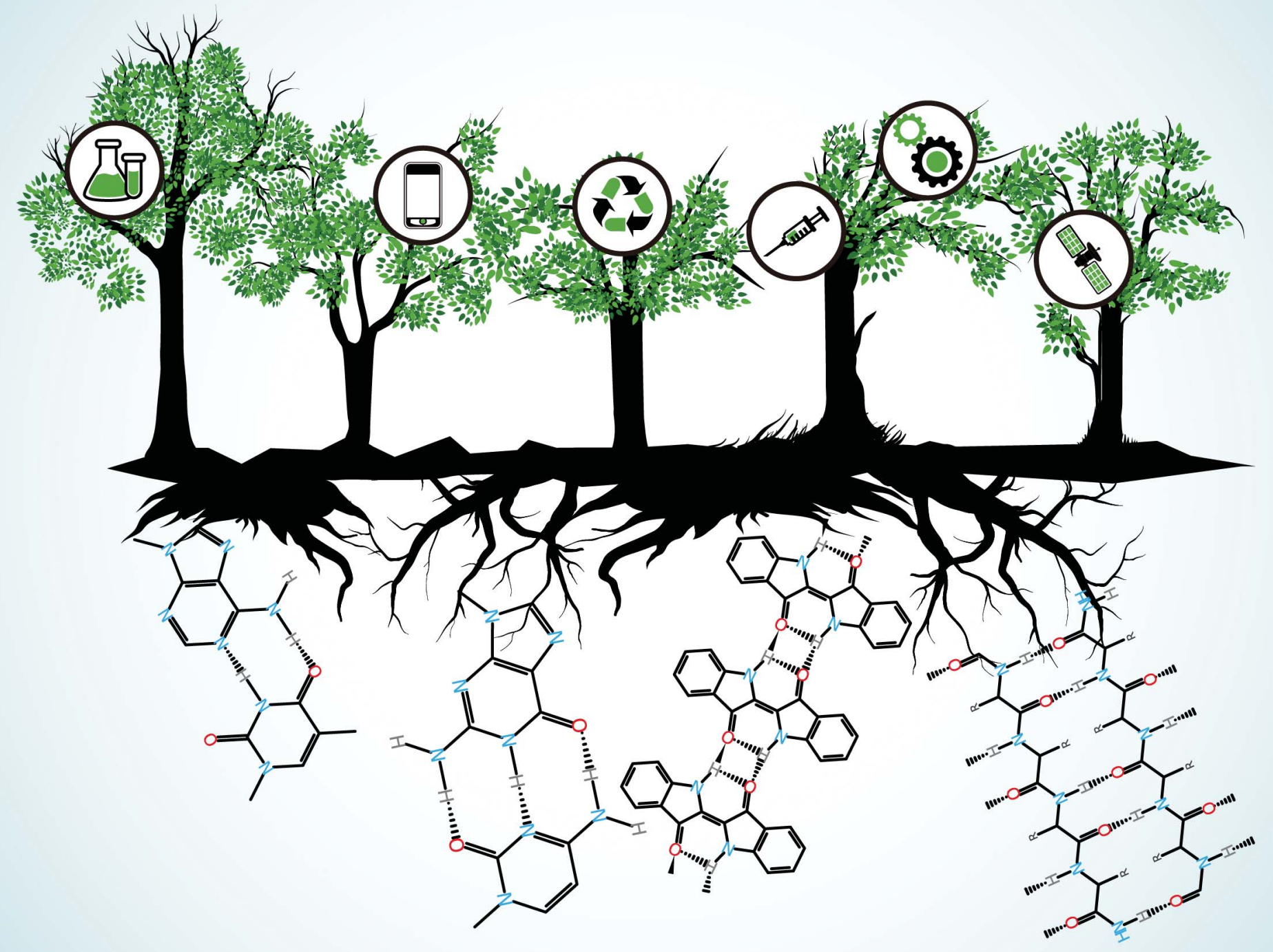

Themed issue: Carbon Bioelectronics 
Cite this: J. Mater. Chem. B, 2013, 1, 3742

Received 10th February 2013

Accepted 27th February 2013

DOI: 10.1039/c3tb20193g

www.rsc.org/MaterialsB

\section{Hydrogen-bonds in molecular solids - from biological systems to organic electronics}

\author{
Eric Daniel Głowacki, ${ }^{\text {*a }}$ Mihai Irimia-Vladu, abc Siegfried Bauer ${ }^{\mathrm{b}}$ \\ and Niyazi Serdar Sariciftci ${ }^{a}$
}

Hydrogen-bonding ( $\mathrm{H}$-bonding) is a relatively strong, highly directional, and specific noncovalent interaction present in many organic molecules, and notably is responsible for supramolecular ordering in biological systems. The $\mathrm{H}$-bonding interactions play a role in many organic electrically conducting materials - in particular in those related to biology, e.g. melanin and indigo. This article aims to highlight recent work on application of nature-inspired $\mathrm{H}$-bonded organic molecules in organic electronic devices. Three topics are covered in this brief review: (1) electrical and ionic conduction in natural $\mathrm{H}$-bonded systems, (2) semiconducting properties of $\mathrm{H}$-bonded organic pigments, and (3) exploitation of $\mathrm{H}$-bonding for supramolecular assembly of organic conductors. $\mathrm{H}$-bonding interactions are ubiquitous in biology, thus making the study of $\mathrm{H}$-bonded organic semiconductors highly pertinent where interfacing of electronics with biological systems is desired.

\section{The hydrogen bond}

Linus Pauling wrote in 1940, "It has been recognized in recent years that under certain conditions an atom of hydrogen is attracted by rather strong forces to two atoms, instead of only one, so that it may be considered to be acting as a bond between them."1 In the 70 years since Pauling, many noncovalent interactions in structural organic chemistry have been classified as H-bonds, creating a difficulty in furnishing a satisfying allencompassing definition of what constitutes an H-bond. A useful explanation is perhaps provided by Peter Atkins in 1989, "A hydrogen bond is a link formed by a hydrogen atom lying between two strongly electronegative atoms". ${ }^{2}$ Many types of $\mathrm{H}$-bonds exist, spanning a wide range of bond energies and geometries. A hydrogen atom can be shared between an "H-bond donor" and an "H-bond acceptor", a molecule with electron lone pairs. H-bond donor character increases with acidity while $\mathrm{H}$-bond acceptor character increases with basicity. Such an interaction can involve an interplay of multiple $\mathrm{H}$-bond acceptors interacting with a single donor. ${ }^{3-5}$ A schematic with the major types of $\mathrm{H}$-bond geometries is shown in the centre of Fig. 1, together with examples where $\mathrm{H}$-bonds play an important role - in biomolecules, dyes and pigments, as well as in ionic conductors and organic semiconductors. This review aims at elucidating the role of $\mathrm{H}$-bonds in these material classes, providing links between the seemingly unrelated dyes and

${ }^{a}$ Linz Institute for Organic Solar Cells (LIOS), Physical Chemistry, Johannes Kepler University,_Linz, Austria.E-mail: eric_daniel.glowacki@jku.at

${ }^{b}$ Soft Matter Physics, Johannes Kepler University, Linz, Austria

'Joanneum Research Forschungsgesellschaft mbH, Weiz, Austria pigments and organic semiconductors, and suggesting new research avenues to merge ionic and electronic devices.

\section{Hydrogen bonds in biological systems}

Though H-bonds are typically weaker than most covalent bonds, with bond energies of the order of 5-65 $\mathrm{kcal} \mathrm{mol}^{-1}$, they are usually significantly stronger than van der Waals interac-

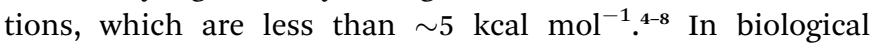
systems the role of $\mathrm{H}$-bonds is ubiquitous. Biochemistry exists in an aqueous environment, where $\mathrm{H}$-bonding interactions are responsible for many of the properties of water, such as high boiling point, dielectric constant, and surface tension. Perhaps the most familiar H-bonded biomolecule in biology is DNA where base pairs are held together by highly specific $\mathrm{H}$-bonding between amine proton donors $\left(-\mathrm{NH}_{2}\right.$ or $\left.-\mathrm{NH}\right)$ and carbonyl group $(=\mathrm{O})$ acceptors. H-bonding is the most significant noncovalent interaction in most polypeptides, i.e. proteins. The two most common protein secondary structures - alpha helices and beta pleated sheets - are both held together by H-bonding between amino acids on adjacent chains, likewise caused by an amine hydrogen-carbonyl interaction of the type $-\mathrm{NH} \cdots \mathrm{O}=$. The antiparallel beta sheet, one of the biologically important structures this type of bonding leads to is illustrated schematically in Fig. 1. Amine-carbonyl bonds are the most frequently encountered but not the only important category of H-bonding in biomolecules: $\mathrm{H}$-bonds between $-\mathrm{OH}$ groups comprise the interchain interactions between polysaccharides such as cellulose and chitin and are thus responsible for the robust mechanical properties of these structural biopolymers. 


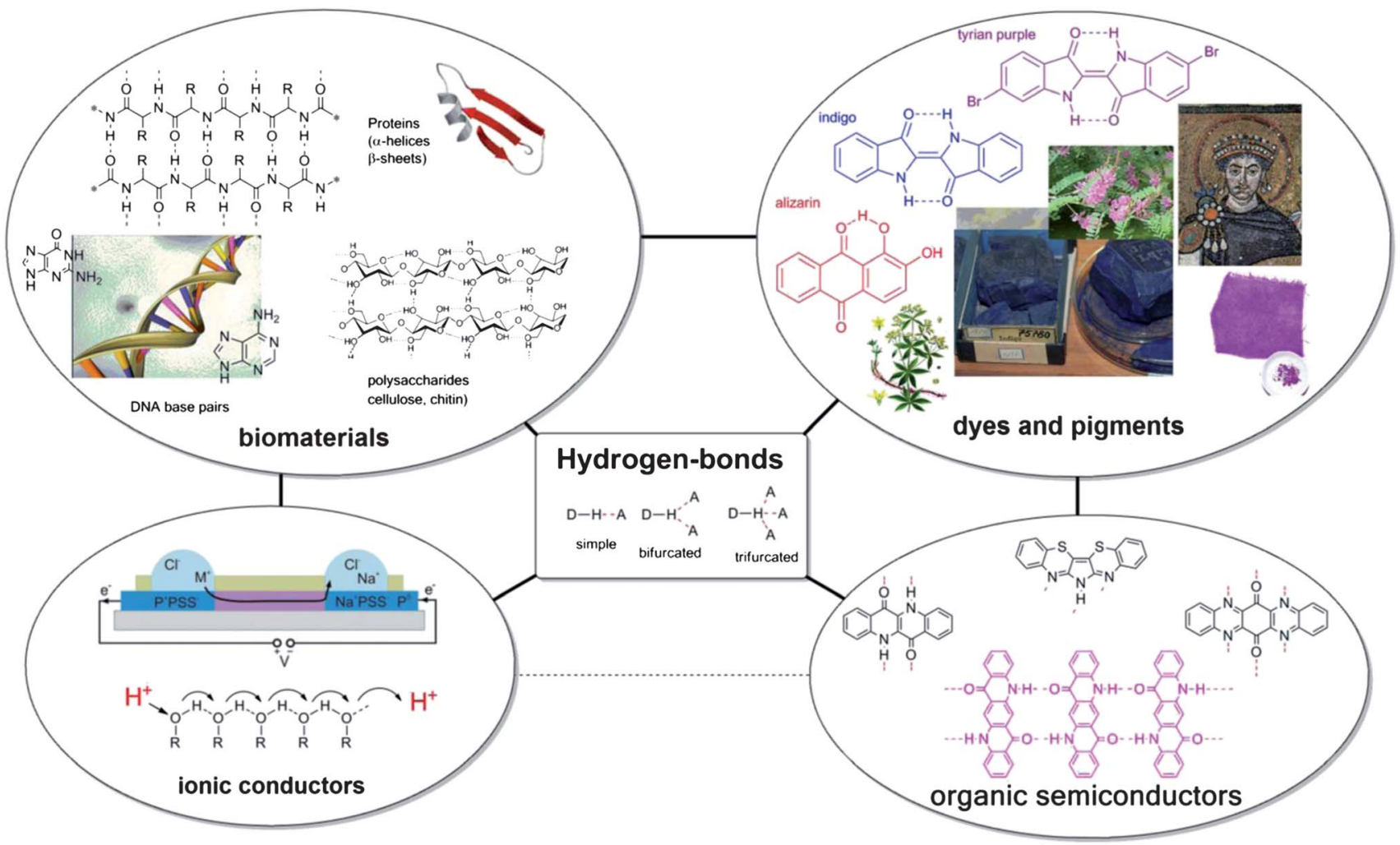

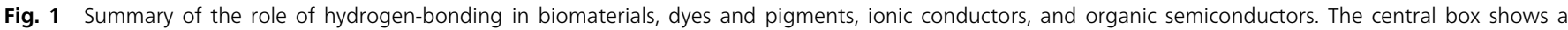

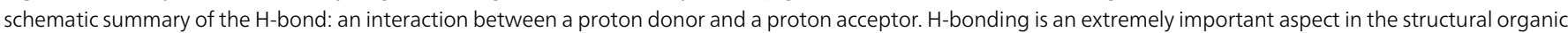

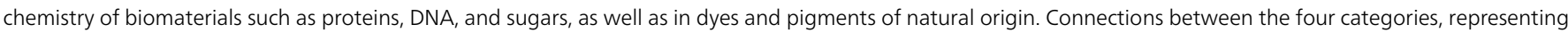

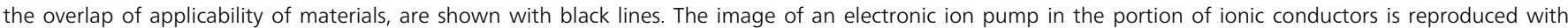
permission from ref. 9 .

Since H-bonding interactions are so common in the natural world it is worthwhile to consider what role they may play in organic conducting and semiconducting materials. At present, the field of organic electronics has evolved from the scientific laboratory into several mature commercial technologies, such as xerography ${ }^{\mathbf{1 0}}$ and organic light-emitting diodes; ${ }^{\mathbf{1 1}}$ with organic photovoltaics ${ }^{\mathbf{1 2}}$ and organic transistor-based circuits ${ }^{\mathbf{1 3}}$ poised to enter the market in the near future. Since early work in the 1960s where it was discovered that conjugated aromatic compounds exhibited semiconducting properties, ${ }^{\mathbf{1 4 - 1 6}}$ research in organic materials for electronics has been focused on materials with extensive $\pi$-conjugation as well as $\pi-\pi$ stacking between adjacent molecules. ${ }^{17}$ The first approach of using an extensive $\pi$-conjugated system yielded conducting conjugated polymers like polyaniline and polyacetylene - 1D metallic conducting systems for which the Nobel Prize in chemistry was awarded in $2000 .^{18-20}$ The ultimate materials science realization of conduction through a $2 \mathrm{D} \pi$-conjugated system is graphene, ${ }^{21}$ an achievement likewise recognized with a Nobel Prize in 2007. Difficulties in fabricating useful devices based on quasi 1D and 2D systems have led to the overall predominance of the second approach: involving conduction through the $\pi-\pi$ stacking of adjacent overlapping conjugated molecules. It is exactly on this second concept that organic semiconductor devices like lightemitting diodes and solar cells are based.
Since H-bonding interactions are so prevalent in nature, and have been exploited extensively in the field of organic crystal engineering for commercial colorant applications, it is surprising that exploiting $\mathrm{H}$-bonding as a molecular design tool for obtaining organic semiconducting and conducing materials has remained largely unexplored. Nevertheless three distinct research avenues into utilizing $\mathrm{H}$-bonding for organic electronic devices are identified, and these are the following: (1) consideration of conduction mechanisms in $\mathrm{H}$-bonded biological materials like DNA, (2) H-bonded organic pigments, used extensively in industrial coloristic applications, and (3) supramolecular H-bond mediated self-assembly of electronically conducting moieties. Because of the important role of $\mathrm{H}$-bonding interactions in biology, organic electronic materials featuring $\mathrm{H}$-bonding could be of substantial interest in emerging organic electronic applications, ${ }^{22-24}$ where interfacing with biological/biomedical systems is desired, such as biosensors, analytical/diagnostic devices, drug delivery systems, and interfaces with neural tissues.

\section{Conduction in $\mathrm{H}$-bonded biomaterials}

Since the earliest days of organic electronic conductor research, $\mathrm{H}$-bonded natural-origin molecules have been the centre of attention. Questions of conductivity in double-stranded DNA 
and RNA and pigmentary melanin have been a topic of fundamental experimental interest. DNA is composed of a deoxyribose sugar chain backbone with planar nucleobases bringing together two complementary DNA strands via H-bonding. The four nucleobases are shown in Fig. 2a. Eley and Spivey observed in 1962 that the $\mathrm{H}$-bonded nucleobase pairs within the double helix of the DNA $\pi-\pi$ stack with a distance of $3.4 \AA$, a value similar to graphite. From temperature-dependent DC conductivity measurements of dry DNA, they concluded that DNA was a semiconductor with conduction arising from thermally excited electrons traversing the stacked base pairs along the chain; and a bandgap of $\sim 2.4 \mathrm{eV} \cdot{ }^{25}$ Using photoinduced electron transfer experiments, in the 1990s and early 2000s several researchers showed that electron transfer can proceed efficiently over distances of several nanometers along the DNA strand. ${ }^{26,27}$ These values are considerably higher than the value of charge transfer efficiency predicted according to Marcus theory. It was

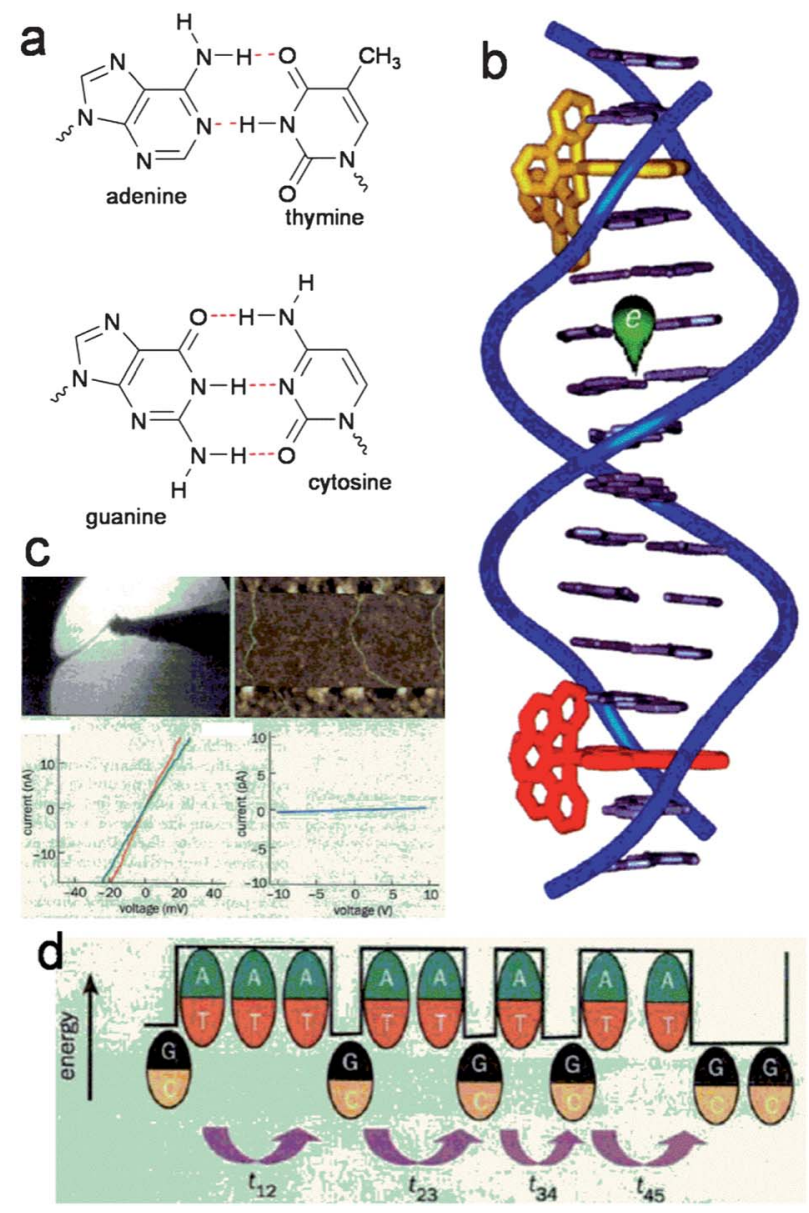

Fig. 2 (a) DNA base pairs held together by complementary $\mathrm{H}$-bonds. (b) Experimental technique of Barton et al. whereby fluorescence quenching via charge transfer of dyes intercalated at different positions along a DNA strand is used to measure electronic conduction through the base pair stack. Reproduced with permission from ref. 28. (c) Examples of contacting individual DNA strands for electrical measurements. These experiments yielded controversial results. Reproduced from ref. 27. (d) Multiple researchers have concluded that conduction proceeds through stacked $\mathrm{G}-\mathrm{C}$ pairs, however $\mathrm{A}-\mathrm{T}$ pairs are barriers. Reproduced from ref. 27. found by varying the nucleobase sequence that the efficiency of charge transfer (via hole transport) was dependent on how well nucleic base molecules were stacked. Several groups have shown that the thymine-adenine sequence has the poorest overlap and thus impedes conduction, while guanine-cytosine or guanine-guanine stacking was superior. In a series of papers by Barton et $a .^{28,29}$ electron transfer reactions were probed by intercalating octahedral metal complexes at various points along a DNA double strand and measuring fluorescence quenching. This technique is shown schematically in Fig. $2 \mathrm{~b}$. These studies concluded that efficient intrastrand electron transport occurs along stacked base pairs.

Direct electrical interrogation of conductivity of DNA strands requires manipulation of strands to lie between two electrodes. Dekker et al. in 2000 used electrostatic trapping techniques to position single strands ( $10 \mathrm{~nm}$ in length) of cytosine-guanine containing DNA between metal nanoelectrodes. ${ }^{30}$ A similar technique was used by Fink and Schönenberger to measure strands of the length $\sim 1 \mu \mathrm{m} .{ }^{31}$ From their temperature-dependent measurements in air and in a vacuum both groups concluded that DNA was a wide-bandgap semiconductor. Other researchers have used solution-deposition methods to stretch strands of DNA across micropatterned electrodes and have also confirmed the semiconducting behaviour of DNA. ${ }^{32}$ Extensive theoretical work on polaronic transport in DNA has been reported by Conwell and coworkers. ${ }^{33,34}$ Nevertheless, other studies using direct electrical contact techniques have indicated that DNA is an electrical insulator at length scales greater than $40 \mathrm{~nm} .{ }^{35}$ It has been suggested that residual salts contribute to conduction and that conductivity derives from an adsorbed water layer on the DNA and that conduction is absent along the $\pi-\pi$ stacked backbone of DNA at longer length-scales. ${ }^{36}$ Significantly, "bulk" processed DNA is an insulator, and in fact has been exploited as such to provide a gate dielectric for organic field-effect transistors. ${ }^{37,38}$ Vacuum-evaporated thinfilms of individual base-pair molecules, such as adenine and guanine, were determined to be good insulators as well. ${ }^{39}$ To-date, no electronic device relying on the conductive properties of DNA has been demonstrated, although conducting polymer-DNA composites exploiting the interesting selfassembly properties of DNA show some more promise. ${ }^{40}$ In conclusion, the existence of electrical conductivity along the $\mathrm{H}$-bonded and $\pi-\pi$ stacked backbone remains controversial, at least for device-relevant length scales.

Eumelanin, the pigment responsible for human skin, hair, and eye color, has attracted significant attention for potential electrical applications. Eumelanin is one of the many melanin pigments which are ubiquitous in nature. Another well-known melanin is the octopus ink, for example. Melanins are composed of a complex mixture of crosslinked oligomeric and polymeric dihydroxyindoles and dihydroxyindole carboxylic acids (Fig. 3a).

These molecules afford extensive H-bonding interactions. McGinness et al. reported in 1974 that melanin behaves as an amorphous semiconductor threshold switch. ${ }^{42}$ This pioneering organic electronic device is shown in Fig. 3b, along with its current-voltage characteristics. This device acted as a threshold 
<smiles>CC(=O)c1[nH]c(C(=O)O)cc1C(=O)c1c(=O)c2c(-c3c(O)c(O)c(C)c4cc(C(=O)O)[nH]c34)c(=O)c(=O)c(=O)c-2c2cc(C(=O)O)[nH]c12</smiles>
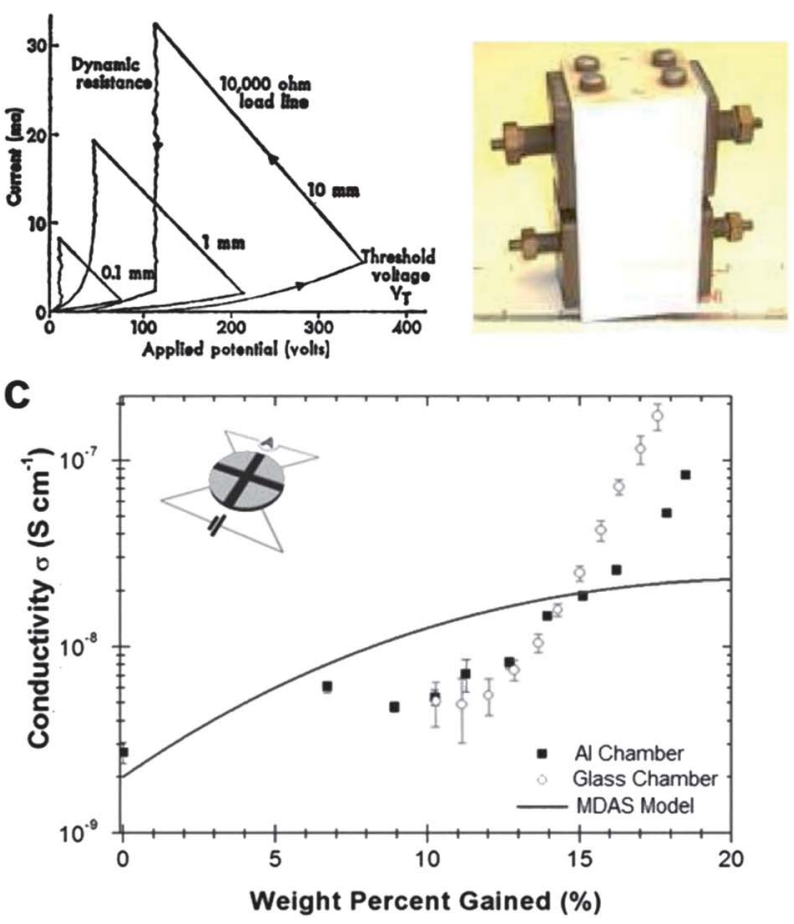

Fig. 3 (a) An example of the polymerized heterocycles that comprise melanin. (b) $I-V$ characteristics and photograph of the original melanin "threshold switch" device fabricated by McGinness. (c) Relationship of conductivity to water uptake in melanin, from ref. 41.

switch, switching to a high-conductivity state once a certain threshold voltage was reached. This process was found to be fully reversible. What remained mysterious, however, was the role of hydration in electrical conductivity, as thoroughly drying the device led to a disappearance of electrical conductivity. X-ray structural studies reported in 1994 on one of the fundamental structural units of melanin, 5,6-indolequinone, showed that these units closely $\pi-\pi$ stack with an interplanar distance of $3.4 \AA{ }^{43}$ Device-quality thin films of melanin with DC conductivities comparable to amorphous silicon, as well as photoconductivity response, have been demonstrated. These films can be prepared on a variety of substrates by solution processing from aqueous solutions. ${ }^{44,45}$ Read-only memory devices have also been fabricated from melanin. ${ }^{46}$ Reconciling various experimental results showing hydration-dependent conductivity and photoconductivity has led to a controversy about the true nature of conduction in melanin. Most researchers applied a MottDavis amorphous semiconductor model (MDAS), where changes in conductivity were rationalized by accepting that the effective dielectric constant increased in the presence of water. This model often fits well to experimental data. ${ }^{47}$ Recent work relying on measurements where differing surface areas of the melanin sample are exposed to water vapour (Fig. 3c) have shown that the MDAS model is most likely incorrect and that in fact hydration-dependent ionic conductivity plays a dominant role in melanin conductivity. ${ }^{41}$ The existence of hybrid ionicelectronic conductivity in melanin suggests that it is an intriguing candidate for bioelectronics interfacing. Indeed recent studies have shown the compatibility of melanin with neuron cells. ${ }^{48}$

\section{Ionic conductors}

Since biological systems rely on transport of ions, e.g. $\mathrm{H}^{+}, \mathrm{Ca}^{2+}$, $\mathrm{Na}^{+}$, and acetylcholine, direct interfacing with biology requires transduction of ionic signals into electronic ones. Significant progress to this end has been made in the past decade, generating a field often called Iontronics. ${ }^{49}$ Solid-state devices based on ion-conducting/electron conducting polymers capable of neural interfacing ${ }^{50-52}$ or delivery of neurotransmitters ${ }^{9,53,54}$ exemplify this effort. H-bonded biomaterials have also been explored as part of this field: polysaccharides such as cellulose or chitin are classic examples of polymeric materials where interchain H-bonding profoundly influences mechanical properties. Though they are electrically insulating, polysaccharides

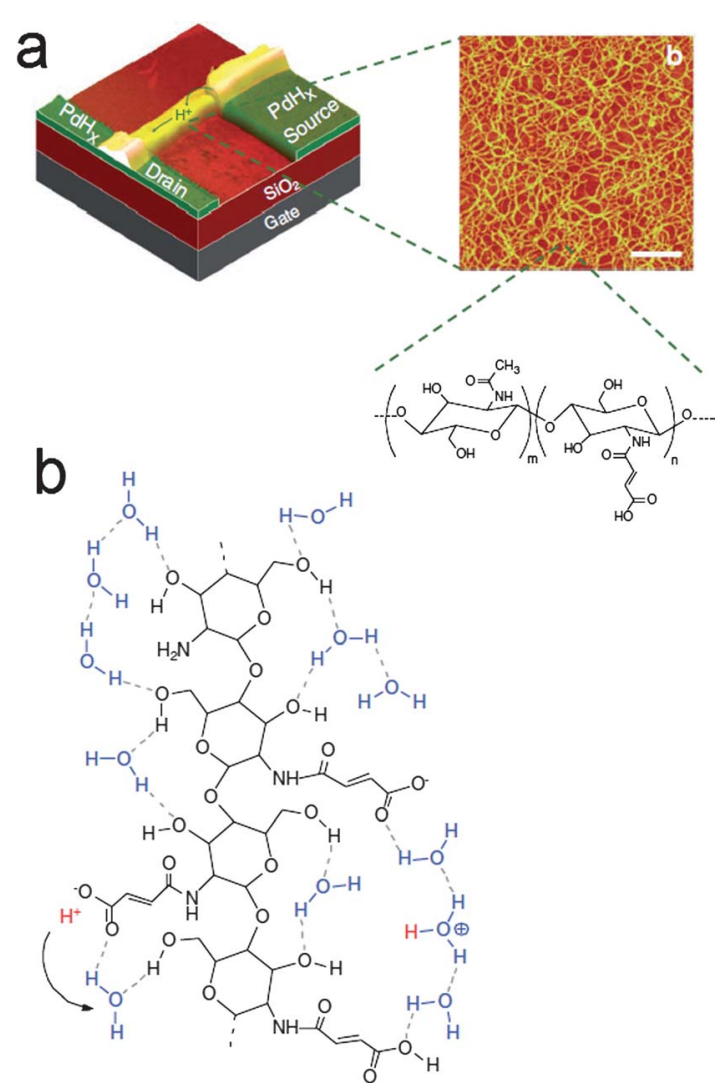

Fig. 4 (a) Bioprotonic transistor based on chitosan as a proton-conducting material. (b) Illustration of the Grotthus-like mechanism of proton conduction along the chitosan polysaccharide. Reproduced with permission from ref. 56. 
can be effective ionic and protonic conductors. Zhong et al. showed in 2011 that solid-state electric field-effect devices can be realized using the polysaccharide chitosan as a protontransporting matrix. ${ }^{55,56}$ A schematic of this device is shown in Fig. 4a. Highly doped silicon and $\mathrm{SiO}_{2}$ serves as the gate electrode and gate dielectric, respectively. Palladium hydride source-drain "protodes" serve as proton-transparent contacts. By applying a gate voltage, protons are either induced or depleted in the proton-conducting chitosan channel, thus providing an electrical modulation of protonic current. Transport of protons along the H-bonded chitosan polymer is illustrated in Fig. 4b. This work represents a successful demonstration of controlling protonic current in a solid-state device based on H-bonded biomaterials. ${ }^{57}$

\section{$\mathrm{H}$-bonded pigments}

Organic pigments are colorants that by definition are insoluble in the media they are applied in. Various paints and inks consist of pigment particles with size ranging from nanometers to several microns mixed with dispersing agents. In all cases, industrial organic pigments owe their poor solubility to strong intermolecular interactions, which are often an interplay of strong $\pi$-stacking and H-bonding. ${ }^{58}$ Diketopyrrolopyrroles (DPPs), quinacridones, perylene diimides (PDIs), and indigos are four of the major classes of industrial colorants today. All of these pigment classes feature H-bonding between - NH hydrogens (donor) and carbonyl groups (acceptor), reminiscent of the same type of $\mathrm{H}$-bonding interactions present in proteins.

The interplay of $\mathrm{H}$-bonding and $\pi$-stacking results in high lattice energies. This fact is reflected in the remarkable thermal stability of these pigments; they are known to sublime at very high temperatures (e.g. $>500{ }^{\circ} \mathrm{C}$ for quinacridone). To the best of our knowledge no $\mathrm{H}$-bonded pigments have been reported to have melting points. Though these pigments are very wellknown for decades, they have received nearly no attention as potential organic semiconductors. The reason for this is that these molecules contain carbonyl and amine groups in conjugated segments. Since under neutral $\mathrm{pH}$ conditions mesomeric forms featuring enol or imine character are unfavourable, carbonyl and amine groups are seen as interrupting $\pi$-conjugation. The prevailing notion among synthetic chemists is that when designing organic semiconducting small molecules or polymers, maximizing $\pi$-conjugation is crucial, and thus amine or carbonyl functional groups are avoided. ${ }^{17,59}$ Recent demonstrations of high carrier mobility in H-bonded pigments containing such functional groups raise the question that perhaps the 'design guidelines' for organic semiconductors could require modification. $\mathrm{H}$-bonded pigment molecules measured in recent years as organic semiconductors are shown in Fig. 5, along with their reported mobility data. The molecules shown will be covered in the following section.

\section{Indigo pigments}

An example of H-bonded molecules that 'break the rules' for obtaining semiconducting behaviour is indigo. Indigo and its dibrominated derivative, tyrian purple, are the oldest and probably best-known organic colorants of natural origin (structures shown in Fig. 5). Indigos are dimers of indole heterocycles, which originate from the amino acid tryptophan. Indigo is formed in certain plants of the indigofera genus, ${ }^{60}$ while tyrian purple originates from shellfish. ${ }^{61}$ Recent work has shown that indigo and tyrian purple, operate as semiconductors in organic field-effect transistor (OFET) devices. ${ }^{62}$ Ambipolar transport of electrons and holes with a mobility of $1 \times 10^{-2} \mathrm{~cm}^{2} \mathrm{~V}^{-1} \mathrm{~s}^{-1}$ was found for indigo. ${ }^{63}$ Interestingly, this device demonstration consisted of entirely biodegradable materials, including the shellac resin as a substrate. The ambipolarity was correlated with an electrochemical behaviour of reversible reduction and oxidation at relatively low potentials. Injection of holes and electrons from a single sourcedrain contact material (in this case $\mathrm{Au}$ ) was facile due to the low bandgap of the material, $1.7 \mathrm{eV}$. Studies of the dibrominated derivative tyrian purple demonstrated a higher mobility, $0.4 \mathrm{~cm}^{2} \mathrm{~V}^{-1} \mathrm{~s}^{-1}$ for both electrons and holes. ${ }^{6,65}$ The carrier mobility in the indigos is correlated with their crystal structure. In most indigos, individual molecules form hydrogen-bonds between adjacent $\mathrm{N}-\mathrm{H} \cdots \mathrm{O}=$ groups along one crystallographic axis. Along a perpendicular axis, the indigo molecules interact via $\pi$-stacking. This stacking is close and relatively cofacial (compared with typical herringbone crystals like the acenes) with an interplanar distance of $3.4 \AA$ and the distance between equivalent positions on neighbouring molecules of 3.6-5 $\AA$ this number can be also higher, depending on substituent groups on the phenyl rings of indigo. The crystal structure of tyrian purple, is shown in Fig. 6.

Intermolecular $\mathrm{H}$-bonds are formed along one crystallographic axis ( $c$-axis) whereby every indigo molecule is $\mathrm{H}$-bonded via single $\mathrm{H}$-bonds to four neighbouring molecules. Meanwhile, $\pi-\pi$ stacking interactions exist along an axis perpendicular to the H-bonding axis, in the case of indigo and tyrian purple the $b$-axis. Thus despite the fact that indigos can be considered, from the traditional perspective of conjugated organic semiconductors, to have minimal $\pi$-conjugation, their intermolecular $\pi$-stacking is apparently sufficient enough to support charge transport with relatively high carrier mobilities, 0.01$0.4 \mathrm{~cm}^{2} \mathrm{~V}^{-1} \mathrm{~s}^{-1}$. Significantly, controlling the crystallographic orientation of indigos during growth of semiconducting thin films is crucial for charge carrier mobility.

Since the $b$-axis is the $\pi-\pi$ stacking axis, this axis must be oriented in the direction of charge transport. For OFET devices, this can be accomplished by modifying the gate dielectric with a hydrophobic layer (such as tetratetracontane ${ }^{\mathbf{6 2 , 6 6}}$ or polyethylene $^{65}$ ) so that the indigo molecules grow in a "standing-up" orientation by virtue of the favourable dispersion forces between the hydrophobic phenyl rings on indigo and the aliphatic substrate.

\section{Quinacridone and DPP}

Linear-fused ring $\mathrm{H}$-bonded molecules can be regarded as an interesting case study, as they are direct analogues of the wellknown acenes, e.g. pentacene. Epindolidione and quinacridone 


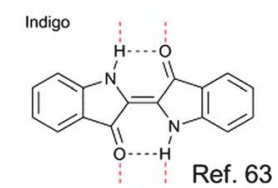

$\mu_{\mathrm{h}}=0.01 \mathrm{~cm}^{2} / \mathrm{Vs}$

$\mu_{\mathrm{e}}=0.01 \mathrm{~cm}^{2} / \mathrm{Vs}$

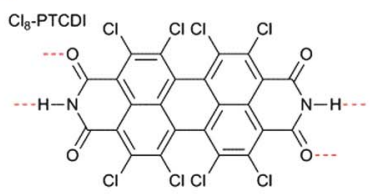

Ref. 95

$\mu_{\mathrm{e}}=0.91 \mathrm{~cm}^{2} \mathrm{Vs}$

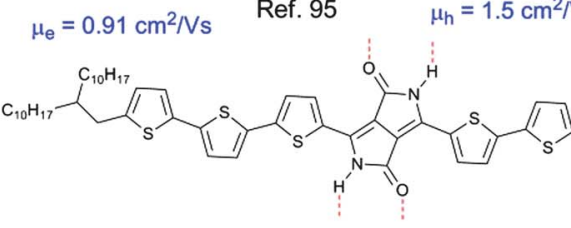

$\mu_{\mathrm{e}}=5.6 \times 10^{-3} \mathrm{~cm}^{2} / \mathrm{Vs}$

$\mu_{\mathrm{h}}=6.7 \times 10^{-3} \mathrm{~cm}^{2} / \mathrm{Vs}$

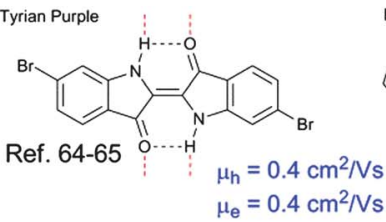

epindolidione

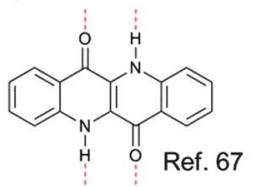

$\mu_{\mathrm{h}}=1.5 \mathrm{~cm}^{2} / \mathrm{ss}$

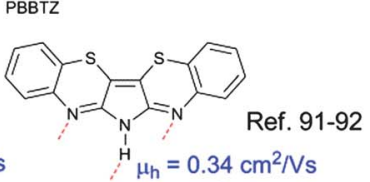

(3.6 $\mathrm{cm}^{2} / \mathrm{Vs}$ in single crystal)
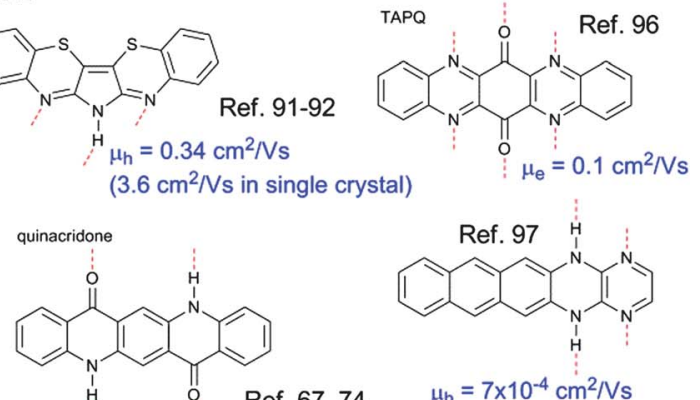

Ref. 67,74

$\mu_{\mathrm{h}}=7 \times 10^{-4} \mathrm{~cm}^{2} / \mathrm{Vs}$

$\mu_{\mathrm{h}}=0.2 \mathrm{~cm}^{2} / \mathrm{Vs}$

$\mu_{\mathrm{e}}=0.01 \mathrm{~cm}^{2} / \mathrm{Vs}$

Fig. 5 Summary of the molecular structures and field-effect mobility measured for the $\mathrm{H}$-bonded pigments covered in this section.

a
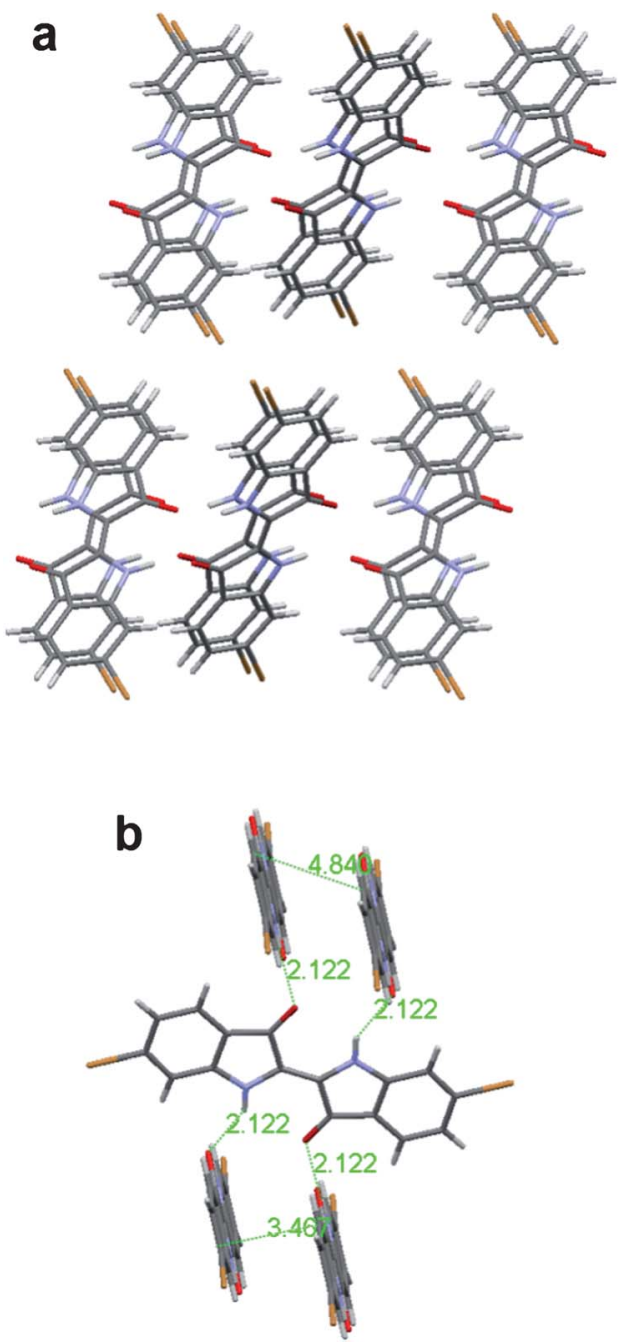

Fig. 6 (a) View down the $b$-axis, or $\pi$-stacking axis, of tyrian purple. (b) Crystal packing in tyrian purple, showing the interplanar, atom-to-atom, and $\mathrm{H}$-bond distances. Each molecule is $\mathrm{H}$-bonded to 4 neighbours. are the 4- and 5-ring analogues of tetracene and pentacene, respectively (Fig. 7a).

In a recent study, ${ }^{67}$ it was shown in identically fabricated OFET devices that epindolidione afforded a significantly higher hole mobility than tetracene, $1.5 \mathrm{~cm}^{2} \mathrm{~V}^{-1} \mathrm{~s}^{-1}$ vs. $0.1 \mathrm{~cm}^{2} \mathrm{~V}^{-1}$ $\mathrm{s}^{-1}$, and that the epindolidione-based devices were highly stable in air for over a hundred days, while tetracene degraded immediately. A comparison of mobility and on/off ratio stability over time for tetracene and epindolidione is shown in Fig. 7b. Quinacridone was found to have a hole mobility of $0.2 \mathrm{~cm}^{2} \mathrm{~V}^{-1} \mathrm{~s}^{-1}$, lower than pentacene, however, the quinacridone devices were highly stable under operation for 140+ days in air while pentacene was far less stable (Fig. 7c). Quinacridone also could support ambipolar transport with appropriate source-drain contact metals. Epindolidione and quinacridone are established industrial pigments, used for high-performance outdoor paints and in inkjet toner formulations. Exploiting a class of materials already mass-produced and cheaply available could enable low-cost large-area organic electronics.

In the case of indigo it has been found that the surface properties of the substrate material are critical for molecular orientation and thus good charge transport. The crucial role of surface properties appears to extend to other H-bonded pigments as well. A 2008 study of OFET devices using quinacridone and DPP using $\mathrm{SiO}_{2}$ as the gate insulator onto which the molecules were processed found mobilities not exceeding $1 \times$ $10^{-5} \mathrm{~cm}^{2} \mathrm{~V}^{-1} \mathrm{~s}^{-1} \cdot{ }^{68}$ Another study from a different group in 2009 found a mobility of $4 \times 10^{-4} \mathrm{~cm}^{2} \mathrm{~V}^{-1} \mathrm{~s}^{-1}$ in quinacridone and also on $\mathrm{SiO}_{2} \cdot{ }^{69}$ The use of an aliphatic passivation layer on the gate dielectric in the 2013 study $^{67}$ of quinacridone significantly increased observed mobilities to $0.2 \mathrm{~cm}^{2} \mathrm{~V}^{-1} \mathrm{~s}^{-1}$. Details concerning the role of the substrate in the growth of films of such materials, however, remain ambiguous.

The crystal structure of quinacridone is known to adopt one of the four polymorphs, two of which, $\alpha^{\mathrm{II}}$ and $\gamma$, feature 4 single 


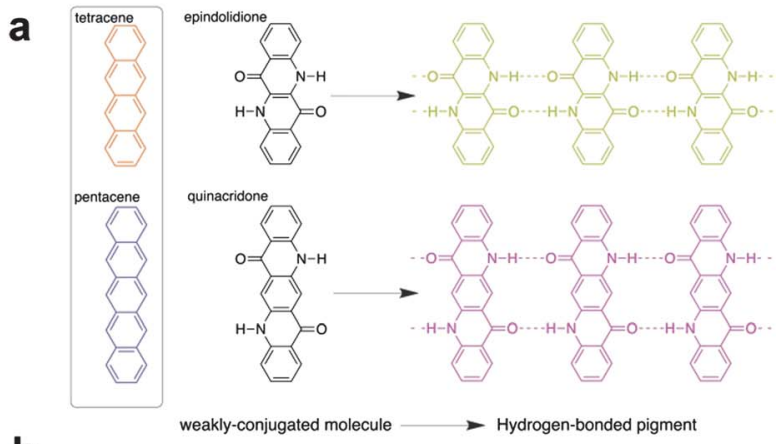

b
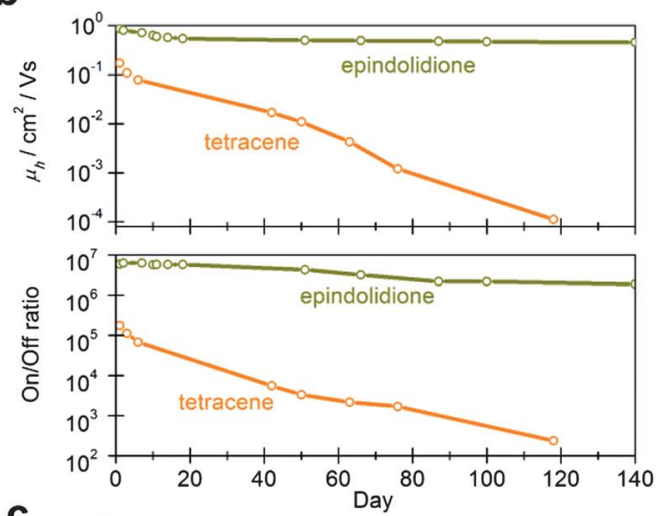

C
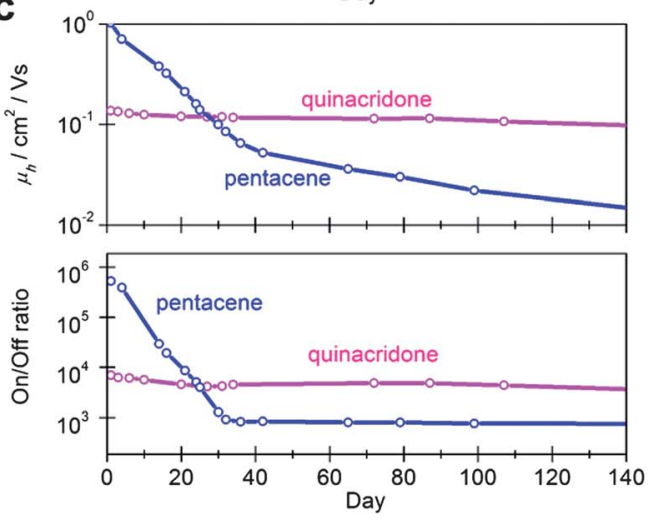

Fig. 7 (a) The acenes and their structural H-bonded analogues, epindolidione and quinacridone, reported in ref. 67. (b) Comparison of operational stability in air of tetracene and epindolidione. (c) Comparison of operational stability in air of pentacene and quinacridone. Reproduced with permission from ref. 67.

H-bonds to 4 neighbours (like the indigos). The other two polymorphs, $\alpha^{\mathrm{I}}$ and $\beta$, are markedly different: in these, quinacridone molecules form double $\mathrm{H}$-bonds to two neighbours, thus forming infinite linear chains. In the perpendicular direction, $\pi-\pi$ stacking exists. ${ }^{70-73}$ This arrangement, known as the "bricks in a wall" or "linear-chain" is shown in Fig. 8. Evaporation of quinacridone onto substrates held at low temperatures $\left(25-70{ }^{\circ} \mathrm{C}\right)$ yields the linear-chain polymorph (probably $\beta$ ) in both OFET $^{67}$ and diode ${ }^{74}$ devices. In these 'linear chain' polymorphs, the $\pi-\pi$ interplanar spacing is $\sim 3.4 \AA$. The "bricks in a wall" arrangement, featuring infinite H-bonded molecular chains, present in $\alpha^{\mathrm{I}}$ and $\beta$ quinacridone, 2,9-dimethylquinacridone, ${ }^{75}$ and most reported DPP pigments, ${ }^{76}$ is indeed very different from the herringbone structures present in many molecular semiconductors such as the acenes.
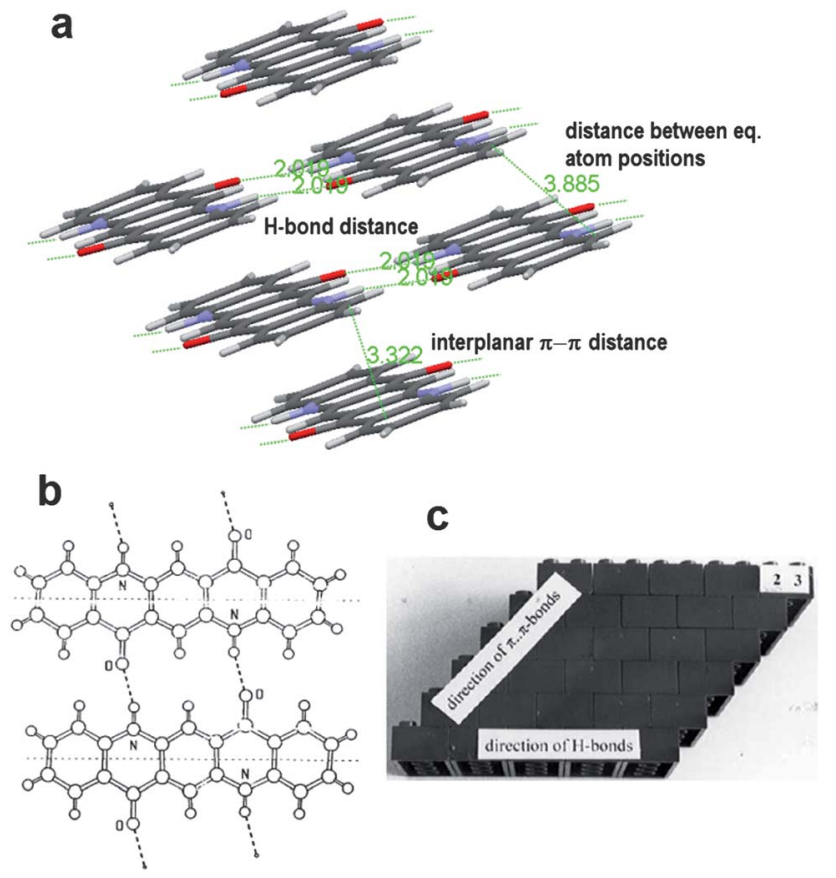

Fig. 8 (a) Crystal packing in $\beta$-quinacridone, which consists of infinite linear chains of H-bonded molecules. (b) Quinacridone H-bonding in the linear-chain polymorphs. (c) Schematic illustration of the "bricks-in-a-wall" crystal packing present in many $\mathrm{H}$-bonded pigments, whereby linear chains of $\mathrm{H}$-bonding propagate along one direction, while there is $\pi-\pi$ stacking perpendicular to the $\mathrm{H}$-bonding direction. Reproduced with permission from ref. 71 .

It should be noted here that much effort ${ }^{77}$ in obtaining superior organic semiconductors has been focused on substituting molecular semiconductors such as to overcome the herringbone crystal formation and enforce a more cofacial $\pi-\pi$ intermolecular interaction, like the one present in the "bricks in a wall" crystal structures. It seems that relying on H-bonding intermolecular interactions can be a useful design technique for achieving such desired crystal structures.

A notable property of all the $\mathrm{H}$-bonded pigment-forming small molecules - including quinacridone, indigo, DPP, and epindolidione - is that their optical absorption undergoes a substantial (50-100 $\mathrm{nm})$ bathochromic shift from a dilute solution to the solid state. ${ }^{78,79}$ Blocking H-bonding, by for example methylating the $-\mathrm{NH}$ groups in indigo ${ }^{79,80}$ or quinacridone, ${ }^{81}$ eliminates this effect, and solution spectra closely resemble solid-state spectra. These observations signal the involvement of strong intermolecular electronic coupling that is caused by intermolecular H-bonding. This phenomenon has been studied in detail for $\gamma$ quinacridone and several DPP pigments. ${ }^{76}$ What has been found is that the large bathochromic shifts arise from an interplay of two effects: (1) the sharing of a proton between adjacent molecules participating in $\mathrm{H}$-bonding changes the local electronic structure of the individual molecules. From a chemical perspective of mesomerism, the interaction of $\mathrm{N}-\mathrm{H}$ and $=\mathrm{O}$ groups of neighbouring molecules can be seen to strengthen the resonance contribution of the imminium and enolate mesomers, essentially enhancing the $\pi$-conjugation of the individual chromophores. 
This phenomenon of "solid state mesomerism" has been reviewed recently by Lincke. ${ }^{70,71}$ (2) H-bonding enhances the electronic coupling between molecules, i.e. there is substantial delocalization of electronic wavefunctions between neighbouring molecules. Studies of polarized optical reflectivity on $\gamma$ quinacridone single crystals showed that the low energy transition that appears in the solid state is oriented along the H-bonding axis. ${ }^{\mathbf{8 1}}$ The results were interpreted in the following way: H-bonding in quinacridone leads to head-to-tail arrangement of the transition dipoles of neighbouring molecules, shifting the absorption band towards longer wavelengths. The photoluminescence of quinacridone in the solid state is more red shifted and broad compared with solution spectra, a phenomenon that has been interpreted as arising from excimer emission. ${ }^{\mathbf{8 2 - 8 5}}$ It was recently found that metal-insulator-metal diodes with quinacridone as the active material showed a pronounced photovoltaic effect and achieved external quantum efficiencies of $\sim 10 \%$, a number three orders of magnitude higher than the related molecule pentacene, as well as most other organic conjugated materials in the absence of a donoracceptor junction. ${ }^{74}$ It was thus proposed that excimeric states forming in quinacridone films can be easily polarized into free charge carriers. Older work, aimed at xerographic applications, has shown that similar efficient photogeneration occurs in DPP pigments as well. ${ }^{86}$ Dissociative excited states in such pigments, thus, can possibly be an interesting research avenue for photodetector and photovoltaic applications that differ from the well-established donor-acceptor heterojunction concept.

DPPs have recently gained a great deal of attention as building blocks for polymers and oligomers with some of the highest mobility (in organic transistors) and power-conversion efficiencies (in photovoltaics).$^{87,88}$ Interestingly, in all of these reports the $-\mathrm{NH}$ groups are substituted with solubilizing aliphatic side groups and the potential of interchain $\mathrm{H}$-bonding has not been explored. Only recently, in 2012, it was shown that, through the use of thermolabile protecting groups, DPP-based H-bonded oligomers and polymers can be solution processed and when deprotected, can support ambipolar transport in its $\mathrm{H}$-bonded form with a field-effect mobility of $\sim 6 \times 10^{-3} \mathrm{~cm}^{2} \mathrm{~V}^{-1} \mathrm{~s}^{-1}$ for both carriers in the $\mathrm{H}$-bonded oligomers, and even in the $10^{-2}$ range for electrons in the case of the polymer. ${ }^{89,90}$

\section{Other H-bonded pigments}

A few other pigment molecules featuring H-bonding have been reported in organic field-effect transistor applications. A littleknown pigment, $6 H$-pyrrolo[3,2- $\left.b: 4,5-b^{\prime}\right]$ bis[1,4]benzothiazine (PBBTZ), shown in Fig. 5, first synthesized in 1968, was utilized by Zhu et al. to fabricate transistors with a hole mobility of $0.34 \mathrm{~cm}^{2} \mathrm{~V}^{-1} \mathrm{~s}^{-1}$ and exceptional stability in air for at least 8 weeks. ${ }^{91}$ It was found that blocking the intermolecular $\mathrm{H}$-bonding in PBBTZ by replacing the amine hydrogen with an aliphatic side group resulted in a drop in mobility of more than three orders of magnitude. The study concluded based on X-ray diffraction and atomic-force microscopy evidence that $\mathrm{H}$-bonding was critical for providing a well-ordered crystalline structure supporting high mobilities. The authors followed up this study by fabricating a single-crystal transistor based on PBBTZ, obtaining a hole mobility of $3.6 \mathrm{~cm}^{2} \mathrm{~V}^{-1} \mathrm{~s}^{-1}$ and an operational stability of at least one year. ${ }^{92}$

Another industrially important family of pigments is that of perylene bisimides. They, in contrast to most of the pigments discussed here, have been widely explored for organic devices as effective electron-transporting materials in transistors and photovoltaic diodes. This subject has been extensively reviewed. ${ }^{93,94}$ Once again, however, the imide - $\mathrm{NH}$ groups in the structure responsible for $\mathrm{H}$-bonding with carbonyl $=\mathrm{O}$ groups on adjacent molecules are blocked with $\mathrm{R}$ groups in nearly every reported study, to our knowledge. A recent exception was reported in 2010, where a perchlorinated perylene bisimide, $\mathrm{Cl}_{8}$-PTCDI, was found to have an electron mobility of $0.91 \mathrm{~cm}^{2} \mathrm{~V}^{-1} \mathrm{~s}^{-1}$, as well as stability in air due to a deep-lying LUMO level. ${ }^{95}$ Though the molecule is highly twisted due to steric effects of the chlorine atoms, the intermolecular H-bonding enforces a "bricks in a wall" crystal structure with a good intermolecular $\pi-\pi$ overlap. Significantly, it was found as in the case of PBBTZ that interrupting H-bonding, this time by replacing the imides with anhydrides, resulted in a three-orderof-magnitude decrease in field-effect mobility.

The group of Miao has published results on $\mathrm{N}$-heteroquinones, pentacene analogues with intermolecular $\mathrm{H}$ bonding. These materials demonstrated an electron mobility of $0.1 \mathrm{~cm}^{2} \mathrm{~V}^{-1} \mathrm{~s}^{-1} .^{96}$ This study was followed by a new set of acene analogues with complementary $\mathrm{H}$-bonding between adjacent pyrazine and dihydropyrazine rings, affording a hole mobility up to $0.7 \mathrm{~cm}^{2} \mathrm{~V}^{-1} \mathrm{~s}^{-1} \cdot{ }^{97}$ These molecules also crystallize in a bricks-in-a-wall geometry, with excellent cofacial $\pi-\pi$ stacking.

\section{Synthetic H-bonded supramolecular semiconducting assemblies}

It is clear from biomolecules such as proteins and DNA that $\mathrm{H}$-bonding is a highly specific tool for self-organizing organic materials. There have been numerous studies on utilization of $\mathrm{H}$-bonding mediated self-organization in the field of synthetic materials science, however, relatively few in the field of organic electronics. A few illustrative examples will be highlighted here.

In the early days of organic semiconducting materials, it was recognized that deviation from planarity of conjugated segments leads to hypsochromic shifts in optical absorption and often poor conductivity. It was found that certain $\mathrm{H}$ bonding interactions introduced along a polymer chain could be used to enforce planarity. Interaction between - $\mathrm{OH}$ groups and the Schiff base $(-\mathrm{C}=\mathrm{N}-)$ for example, can lead to substantial bathochromic shifts in absorption of polyazomethine polymers due to planarization of the polymer. ${ }^{98}$ Various approaches involving $\mathrm{H}$-bonding between adjacent chains can also be exploited to planarize polymers. ${ }^{\mathbf{9 9 , 1 0 0}}$

The next level of utilizing $\mathrm{H}$-bonding is making conducting supramolecular assemblies. H-bond mediated supramolecular semiconducting systems have been demonstrated for fieldeffect transistor and light-emitting diode applications. Schenning, Meijer, and coworkers in Eindhoven have done the most 
extensive work on this concept up-to-date. In one demonstration, H-bonding was utilized to drive the self-assembly of hole-transporting oligo( $p$-phenylenevinylene)s and electrontransporting perylene bisimides (Fig. 9a). ${ }^{\mathbf{1 0 1}}$ The resultant supramolecular composite consisted of uniform rod-like domains which supported ambipolar transport. These H-bonded ambipolar dyads afforded a low mobility, $\sim 1 \times$ $10^{-7} \mathrm{~cm}^{2} \mathrm{~V}^{-1} \mathrm{~s}^{-1}$. A mixture, however, of the two components without $\mathrm{H}$-bonding moieties yielded donor-acceptor complexes with no field-effect mobility at all. The H-bonding thus enforces a supramolecular morphology supporting two independent pathways for charge transport. In a subsequent report, white light-emitting electroluminescent devices were achieved by using an H-bonded supramolecular polymer consisting of red, green, and blue emitters. ${ }^{102}$ Each of the chromophores was functionalized with self-complementary quadruple H-bondforming ureidopyrimidinone units at both ends (Fig. 9b).

These molecules self-assemble into supramolecular polymers which can efficiently support resonant energy transfer (Fig. 9c). At a certain mixing ratio, white fluorescence in solution is observed (Fig. 9d and e), a fact that was exploited to fabricate organic-light emitting diodes that demonstrated white electroluminescence. The utilization of complementary H-bonding afforded several advantages relative to mixing unfunctionalized chromophore components: (1) no phase separation is observed, (2) the H-bonded system provided superior film-forming properties, and (3) white-light emission is significantly more efficient. The work of the Eindhoven group in supramolecular $\mathrm{H}$-bonded conjugated organic materials has been recently reviewed. ${ }^{103,104}$
Improved charge carrier mobility was demonstrated in another recent study of solution-processable supramolecular assemblies. ${ }^{105}$ Perylene bisimides bearing melamine sidegroups were dissolved in organic solvents by mixing with complementary H-bonding barbiturate or cyanurate. Spin-coating these solutions affords highly organized lamellar assemblies with an electron field-effect mobility up to $1 \times$ $10^{-4} \mathrm{~cm}^{2} \mathrm{~V}^{-1} \mathrm{~s}^{-1}$ (Fig. 10). This work is particularly interesting for the reliance of multiple components to achieve

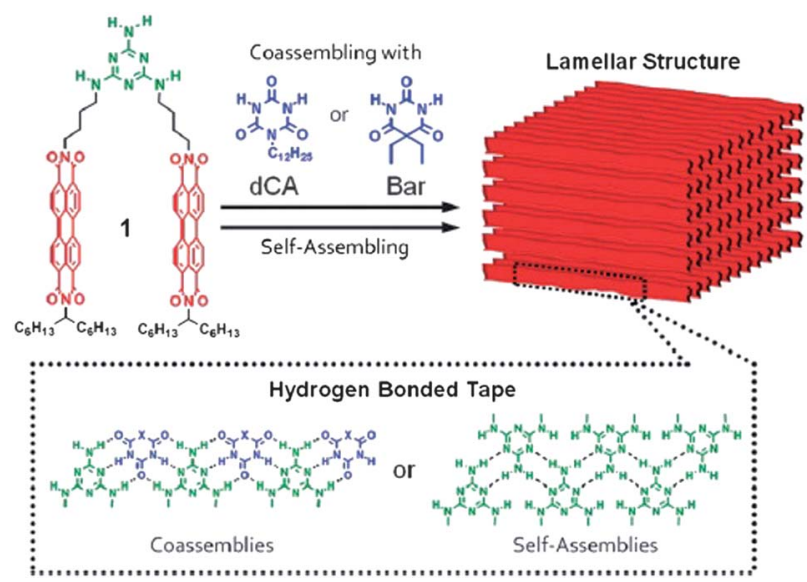

Fig. 10 Perylene bisimide conjugated dyes functionalized with melamine segments, providing self-assembly to yield H-bonded self-organized "tapes" allowing electron-transport through stacked perylene bisimide moieties. Reproduced with permission from ref. 105.

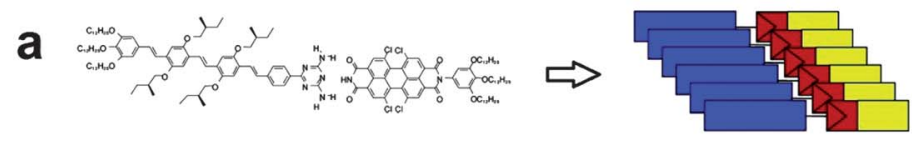

b

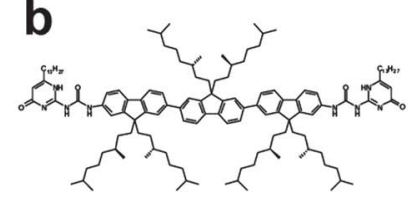

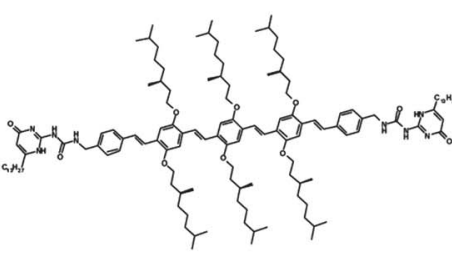

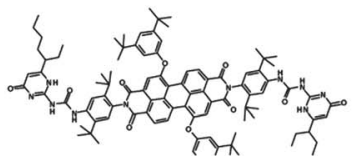

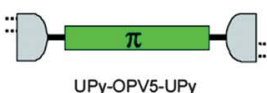

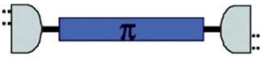

UPy-OF3-UPy

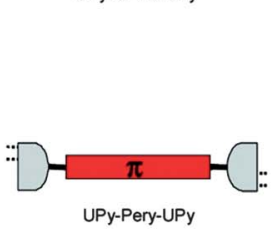

C
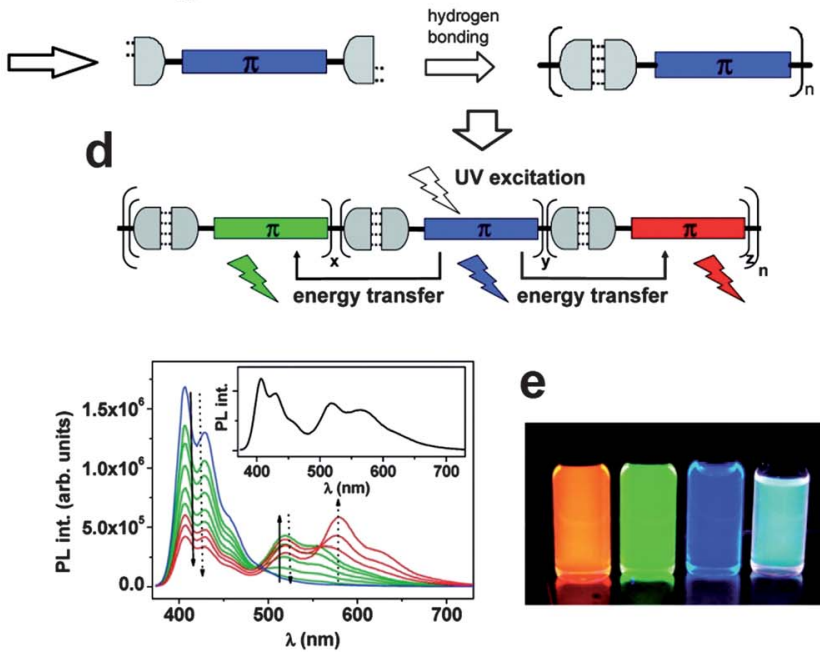

e

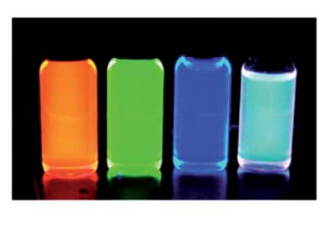

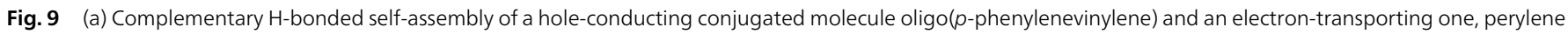

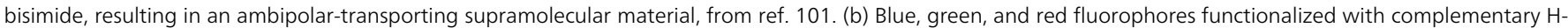

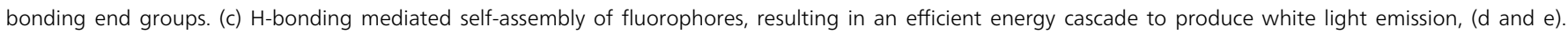
Reproduced with permission from ref. 102. 
coassemblies, highlighting the large degree of tunability that can be accessed by using H-bonding for supramolecular assemblies.

\section{Conclusions}

Since Pauling's recognition of the crucial role that H-bonding plays in biological materials, such as proteins, it has become clear that H-bonding is an extremely important noncovalent interaction ubiquitous in nature and remarkable for self-organization of complex molecular systems. H-bonding is likewise found in natural dyes and pigments and has been explored in the crystal engineering of industrially important pigments. Only recently research has been started to elucidate the role that $\mathrm{H}$ bonding can play in ionic and electronic conducting materials: natural systems such as DNA and melanin have shown promise that they can be used as electronic materials directly. H-bonded pigments, many of which are of natural origin, such as indigo, have proven recently to be highly promising organic semiconductors, outperforming many established materials especially in terms of operational stability. Significantly, many of these molecules are already known to be nontoxic and biodegradable. Finally, electronic and ionic-conducting conjugated building blocks can be functionalized with H-bonding moieties that accomplish self-assembly into useful supramolecular structures. All three of these research directions converge on the principle of employing $\mathrm{H}$-bonds to control ordering in organic solids. Since exactly these types of ordering interactions are prevalent throughout biological systems, realization of organic electronics based on $\mathrm{H}$-bonded materials represents a major step in the direction of biointegrated electronics.

We wish to warmly thank Dr Uwe Monkowius of the JKU for valuable discussions and collaboration on X-ray diffraction experiments. Support of the Austrian Science Fund (FWF) within the Wittgenstein Prize and the ERC within the Advanced Investigators Grant "Soft-Map” is gratefully acknowledged.

\section{Notes and references}

1 L. Pauling, The Nature of the Chemical Bond and the Structure of Molecules and Crystals. An Introduction to Modern Structural Chemistry, Oxford University Press, London, 2nd edn, 1940.

2 P. Atkins, General Chemistry, Scientific American Books, New York, 1989.

3 G. R. Desiraju, J. Mol. Struct., 2003, 656, 5-15.

4 G. R. Desiraju, Cryst. Growth Des., 2011, 11, 896-898.

5 C. B. Aakeroy and K. R. Seddon, Chem. Soc. Rev., 1993, 22, 397-407.

6 M. Meot-Ner (Mautner), Chem. Rev., 2005, 105, 213-284.

7 G. R. Desiraju, Mol. Cryst. Liq. Cryst., 1992, 211, 63-74.

8 P. Gilli and G. Gilli, J. Mol. Struct., 2010, 972, 2-10.

9 K. Tybrandt, K. C. Larsson, S. Kurup, D. T. Simon, P. Kjäll, J. Isaksson, M. Sandberg, E. W. H. Jager, A. Richter-Dahlfors and M. Berggren, Adv. Mater., 2009, 21, 4442-4446.

10 K. Y. Law, Chem. Rev., 1993, 93, 449-486.
11 S. Hofmann, M. Thomschke, B. Lüssem and K. Leo, Opt. Express, 2011, 19, A1250-A1264.

12 G. Dennler, M. C. Scharber and C. J. Brabec, Adv. Mater., 2009, 21, 1323-1338.

13 J. Zaumseil and H. Sirringhaus, Chem. Rev., 2007, 107, 1296-1323.

14 H. Akamatu and H. Inokuchi, J. Chem. Phys., 1950, 18, 810811.

15 H. Inokuchi, Org. Electron., 2006, 7, 62-76.

16 M. Pope and C. E. Swenberg, Electronic Processes in Organic Crystals and Polymers, Oxford University Press, 2nd edn, 1999.

17 A. Facchetti, Chem. Mater., 2011, 23, 733-758.

18 C. K. Chiang, M. A. Druy, S. C. Gau, A. J. Heeger, E. J. Luis, A. G. Mac Diarmid, Y. W. Park and H. Shirakawa, J. Am. Chem. Soc., 1978, 100, 1013-1015.

19 W.-P. S. A. J. Heeger, S. Kivelson and J. R. Schrieffer, Rev. Mod. Phys., 1988, 60, 781-850.

20 A. J. Heeger, Rev. Mod. Phys., 2001, 73, 681-700.

21 A. K. Geim and K. S. Novoselov, Nat. Mater., 2007, 6, 183191.

22 M. D. Angione, R. Pilolli, S. Cotrone, M. Magliulo, A. Mallardi, G. Palazzo, L. Sabbatini, D. Fine, A. Dodabalapur, N. Cioffi and L. Torsi, Mater. Today, 2011, 14, 424-433.

23 G. G. Malliaras, Biochim. Biophys. Acta, 2012, DOI: 10.1016/ j.bbagen.2012.10.007; and other articles in this issue.

24 M. Irimia-Vladu, E. D. Głowacki, G. Voss, S. Bauer and N. S. Sariciftci, Mater. Today, 2012, 15, 340-346; P. Meredith, C. J. Bettinger, M. Irimia-Vladu, A. B. Mostert and P. E. Schwenn, Rep. Prog. Phys., 2013, 76, 034501.

25 D. D. Eley and D. I. Spivey, Trans. Faraday Soc., 1962, 58, 411-415.

26 B. Giese, J. Amaudrut, A. K. Köhler, M. Spormann and S. Wessely, Nature, 2001, 412, 318-320.

27 M. A. Ratner and C. Dekker, Phys. World, 2001, 29-33.

28 R. E. Holmlin, P. J. Dandliker and J. K. Barton, Angew. Chem., 1997, 36, 2714-2730.

29 S. O. Kelley and J. K. Barton, Science, 1999, 283, 375-381.

30 D. Porath, A. Bezryadin, S. de Vries and C. Dekker, Nature, 2000, 403, 635-638.

31 H. W. Fink and C. Schönenberger, Nature, 1999, 398, 407410.

32 J. Wang, Phys. Rev. B: Condens. Matter Mater. Phys., 2008, 78, 245304.

33 E. M. Conwell, Proc. Natl. Acad. Sci. U. S. A., 2005, 102, 87958799.

34 V. M. Kucherov, C. D. Kinz-Thompson and E. M. Conwell, J. Phys. Chem. C, 2010, 114, 1663-1666.

35 A. J. Storm, J. van Noort, S. de Vries and C. Dekker, Appl. Phys. Lett., 2001, 79, 3881.

36 N. P. Armitage, M. Briman and G. Grüner, Phys. Status Solidi $B, 2004,241,69-75$.

37 P. Stadler, K. Oppelt, T. B. Singh, J. G. Grote, R. Schwödiauer, S. Bauer, H. Piglmayer-Brezina, D. Bäuerle and N. S. Sariciftci, Org. Electron., 2007, 8, 648-654. 
38 C. Yumusak, T. B. Singh, N. S. Sariciftci and J. G. Grote, Appl. Phys. Lett., 2009, 95, 263304.

39 M. Irimia-Vladu, P. A. Troshin, M. Reisinger, L. Shmygleva, Y. Kanbur, G. Schwabegger, M. Bodea, R. Schwödiauer, A. Mumyatov, J. W. Fergus, V. F. Razumov, H. Sitter, N. S. Sariciftci and S. Bauer, Adv. Funct. Mater., 2010, 20, 4069-4076; M. Irimia-Vladu, P. A. Troshin, M. Reisinger, G. Schwabegger, M. Ullah, R. Schwoediauer, A. Mumyatov, M. Bodea, J. W. Fergus and V. F. Razumov, Org. Electron., 2010, 11, 1974-1990; M. Irimia-Vladu, N. S. Sariciftci and S. Bauer, J. Mater. Chem., 2011, 21, 1350-1361.

40 M. Hamedi, A. Elfwing, R. Gabrielsson and O. Inganäs, Small, 2012, 9, 363-368.

41 A. Bernardus Mostert, B. J. Powell, I. R. Gentle and P. Meredith, Appl. Phys. Lett., 2012, 100, 093701.

42 J. McGinness, P. Corry and P. Proctor, Science, 1974, 183, 853-855.

43 G. W. Zajac, J. M. Gallas, M. Eisner, S. C. Moss and A. E. Alvarado-Swaisgood, Biochim. Biophys. Acta, 1994, 1199, 271-278.

44 J. P. Bothma, J. de Boor, U. Divakar, P. E. Schwenn and P. Meredith, Adv. Mater., 2008, 20, 3539-3542.

45 M. Ambrico, P. F. Ambrico, A. Cardone, T. Ligonzo, S. R. Cicco, R. Di Mundo, V. Augelli and G. M. Farinola, Adv. Mater., 2011, 23, 3332-3336.

46 M. Ambrico, A. Cardone, T. Ligonzo, V. Augelli, P. F. Ambrico, S. Cicco, G. M. Farinola, M. Filannino, G. Perna and V. Capozzi, Org. Electron., 2010, 11, 1809-1814.

47 P. Meredith and T. Sarna, Pigm. Cell Res., 2006, 19, 572-594. 48 C. J. Bettinger, J. P. Bruggeman, A. Misra, J. T. Borenstein and R. Langer, Biomaterials, 2009, 30, 3050-3057.

49 L. Zeng, C. W. Tang and S. H. Chen, Appl. Phys. Lett., 2010, 97, 053305.

50 D. Khodagholy, T. Doublet, M. Gurfinkel, P. Quilichini, E. Ismailova, P. Leleux, T. Herve, S. Sanaur, C. Bernard and G. G. Malliaras, Adv. Mater., 2011, 23, H268-H272.

51 S. M. Richardson-Burns, J. L. Hendricks and D. C. Martin, J. Neural Eng., 2007, 4, L6-L13.

52 M. Muskovich and C. J. Bettinger, Adv. Healthcare Mater., 2012, 1, 248-266.

53 J. Isaksson, P. Kjäll, D. Nilsson, N. D. Robinson, M. Berggren and A. Richter-Dahlfors, Nat. Mater., 2007, 6, 673-679.

54 M. H. Bolin, K. Svennersten, D. Nilsson, A. Sawatdee, E. W. H. Jager, A. Richter-Dahlfors and M. Berggren, Adv. Mater., 2009, 21, 4379-4382.

55 C. Zhong, A. Kapetanovic, Y. Deng and M. Rolandi, Adv. Mater., 2011, 23, 4776-4781.

56 C. Zhong, Y. Deng, A. F. Roudsari, A. Kapetanovic, M. P. Anantram and M. Rolandi, Nat. Commun., 2011, 2, 476.

57 A. Cooper, C. Zhong, Y. Kinoshita, R. S. Morrison, A. Kapetanovic, M. P. Anantram, M. Rolandi and M. Zhang, J. Mater. Chem., 2012, 22, 3105-3109.

58 H. Zollinger, Color Chemistry: Syntheses, Properties, and Applications of Organic Dyes and Pigments, Wiley-VCH, Weinheim, 3rd edn, 2003.
59 A. Pron and P. Rannou, Prog. Polym. Sci., 2002, 27, 135-190. $60 \mathrm{M}$. Seefelder, Indigo in culture, science, and technology, Ecomed verlag, Landsberg, 2nd edn, 1994.

61 C. J. Cooksey, Molecules, 2001, 6, 736-769.

62 E. D. Głowacki, G. Voss, L. Leonat, M. Irimia-Vladu, S. Bauer and N. S. Sariciftci, Isr. J. Chem., 2012, 52, 540-551.

63 M. Irimia-Vladu, E. D. Głowacki, P. A. Troshin, G. Schwabegger, L. Leonat, D. K. Susarova, O. Krystal, M. Ullah, Y. Kanbur, M. A. Bodea, V. F. Razumov, H. Sitter, S. Bauer and N. S. Sariciftci, Adv. Mater., 2012, 24, 375-380.

64 E. D. Głowacki, L. Leonat, G. Voss, M.-A. Bodea, Z. Bozkurt, A. M. Ramil, M. Irimia-Vladu, S. Bauer and N. S. Sariciftci, AIP Adv., 2011, 1, 042132-042137.

65 Y. Kanbur, M. Irimia-Vladu, E. D. Głowacki, G. Voss, M. Baumgartner, G. Schwabegger, L. Leonat, M. Ullah, H. Sarica, S. Erten-Ela, R. Schwödiauer, H. Sitter, Z. Küçükyavuz, S. Bauer and N. S. Sariciftci, Org. Electron., 2012, 13, 919-924.

66 A. Opitz, M. Horlet, M. Kiwull, J. Wagner, M. Kraus and W. Brütting, Org. Electron., 2012, 13, 1614-1622.

67 E. D. Głowacki, M. Irimia-Vladu, M. Kaltenbrunner, J. Gąsiorowski, M. S. White, U. Monkowius, G. Romanazzi, G. P. Suranna, P. Mastrorilli, T. Sekitani, S. Bauer, T. Someya, L. Torsi and N. S. Sariciftci, Adv. Mater., 2013, 25, 1563-1569.

68 H. Yanagisawa, J. Mizuguchi, S. Aramaki and Y. Sakai, Jpn. J. Appl. Phys., 2008, 47, 4728-4731.

69 D. Berg, C. Nielinger, W. Mader and M. Sokolowski, Synth. Met., 2009, 159, 2599-2602.

70 G. Lincke, Dyes Pigm., 2000, 44, 101-122.

71 G. Lincke, Dyes Pigm., 2002, 52, 169-181.

72 E. F. Paulus, F. J. J. Leusen and M. U. Schmidt, CrystEngComm, 2007, 9, 131-143.

73 N. Panina, F. J. J. Leusen, F. F. B. J. Janssen, P. Verwer, H. Meekes, E. Vlieg and G. Deroover, J. Appl. Crystallogr., 2007, 40, 105-114.

74 E. D. Głowacki, L. Leonat, M. Irimia-Vladu, R. Schwödiauer, M. Ullah, H. Sitter, S. Bauer and N. Serdar Sariciftci, Appl. Phys. Lett., 2012, 101, 023305.

75 J. Mizuguchi, T. Senju and M. Sakai, Z. Kristallogr., 2002, 217, 525-526.

76 J. Mizuguchi, J. Phys. Chem. A, 2000, 104, 1817-1821.

77 J. E. Anthony, Chem. Rev., 2006, 106, 5028-5048.

78 S. S. Labana and L. L. Labana, Chem. Rev., 1967, 67, 1-18.

79 M. Wyman and J. Weinstein, J. Org. Chem., 1956, 78, 23872390.

80 J. Weinstein and G. M. Wyman, J. Org. Chem., 1956, 78, 4007-4010.

81 J. Mizuguchi and T. Senju, J. Phys. Chem. B, 2006, 110, 19154-19161.

82 J. Kalinowski, W. Stampor, P. Di Marco and V. Fattori, Chem. Phys., 1994, 182, 341-352.

83 L. Rossi, G. Bongiovanni, G. Lanzani, A. Mura, A. Borghesi, R. Tubino and J. Kalinowski, Adv. Mater. Opt. Electron., 1997, 7, 83-86. 
84 L. Rossi, G. Bongiovanni, J. Kalinowski, G. Lanzani, A. Mura, M. Nisoli and R. Tubino, Chem. Phys. Lett., 1996, 257, 545-551.

85 L. Rossi, G. Bongiovanni, A. Borghesi, G. Lanzani, J. Kalinowski, A. Mura and R. Tubino, Synth. Met., 1997, 84, 873-874.

86 J. Mizuguchi and S. Homma, J. Appl. Phys., 1989, 66, 31043110.

87 S. Qu and H. Tian, Chem. Commun., 2012, 48, 3039-3051.

88 C. B. Nielsen, M. Turbiez and I. Mcculloch, Adv. Mater., 2012, DOI: 10.1002/adma.201201795.

89 Y. Suna, J.-I. Nishida, Y. Fujisaki and Y. Yamashita, Org. Lett., 2012, 14, 3356-3359.

90 J. Lee, A.-R. Han, J. Hong, J. H. Seo, J. H. Oh and C. Yang, Adv. Funct. Mater., 2012, 22, 4128-4138.

91 W. Hong, Z. Wei, H. Xi, W. Xu, W. Hu, Q. Wang and D. Zhu, J. Mater. Chem., 2008, 18, 4814-4820.

92 Z. Wei, W. Hong, H. Geng, C. Wang, Y. Liu, R. Li, W. Xu, Z. Shuai, W. Hu, Q. Wang and D. Zhu, Adv. Mater., 2010, 22, 2458-2462.

93 X. Zhan, A. Facchetti, S. Barlow, T. J. Marks, M. A. Ratner, M. R. Wasielewski and S. R. Marder, Adv. Mater., 2011, 23, 268-284.

94 C. Huang, S. Barlow and S. R. Marder, J. Org. Chem., 2011, 76, 2386-2407.
95 M. Gsänger, J. H. Oh, M. Könemann, H. W. Höffken, A.-M. Krause, Z. Bao and F. Würthner, Angew. Chem., 2010, 49, 740-743.

96 Q. Tang, Z. Liang, J. Liu, J. Xu and Q. Miao, Chem. Commun., 2010, 46, 2977-2979.

97 Z. He, D. Liu, R. Mao, Q. Tang and Q. Miao, Org. Lett., 2012, 14, 1050-1053.

98 C. Yang and S. A. Jenekhe, Chem. Mater., 1991, 3, 878-887.

99 A. P. Monkman, L.-O. Pålsson, R. W. T. Higgins, C. Wang, M. R. Bryce, A. S. Batsanov and J. A. K. Howard, J. Am. Chem. Soc., 2002, 124, 6049-6055.

100 M. Vetrichelvan and S. Valiyaveettil, Chem.-Eur. J., 2005, 11, 5889-5898.

101 P. Jonkheijm, N. Stutzmann, Z. Chen, D. M. De Leeuw, E. W. Meijer, A. P. H. J. Schenning and F. Wu, J. Am. Chem. Soc., 2006, 128, 9535-9540.

102 R. Abbel, C. Grenier, M. J. Pouderoijen, J. W. Stouwdam, P. E. L. G. Leclère, R. P. Sijbesma, E. W. Meijer and A. P. H. J. Schenning, J. Am. Chem. Soc., 2009, 131, 833-843. 103 F. J. M. Hoeben, P. Jonkheijm, E. W. Meijer and A. P. H. J. Schenning, Chem. Rev., 2005, 105, 1491-1546.

104 D. J. Broer, C. M. W. Bastiaansen, M. G. Debije and A. P. H. J. Schenning, Angew. Chem., 2012, 51, 7102-7109.

105 T. Seki, Y. Maruya, K. Nakayama, T. Karatsu, A. Kitamura and S. Yagai, Chem. Commun., 2011, 47, 12447-12449. 